\title{
Estabilidad de constituyentes bioquímicos conservados en dos tipos de tubos primarios: estudio mediante el criterio combinado de variabilidad analítica y biológica

\author{
Stability of biochemical constituents conserved in two types of primary tubes: study \\ by the combined criterion of analytical and biological variability
}

\author{
Italo Moisés Saldaña Orejón ${ }^{1}$, Miguel Angel Benites Ricra², Francisco Javier Ortiz Canasa ${ }^{3}$ \\ Tecnólogo Médico. Departamento de Patología Clínica, Hospital Nacional Edgardo Rebagliati Martins. Lima, Perú. \\ Estudiante de Tecnología Médica. Universidad Alas Peruanas. Lima, Perú. \\ Bachiller en Tecnología Médica. Universidad Alas Peruanas. Lima, Perú.
}

Correspondencia:

Italo Moisés Saldaña Orejónimso_

biochemical@yahoo.es

Recibido: 20 de marzo 2018

Aprobado: 11 de abril 2018

Conflictos de interés: Los autores declaran no tener conflictos de interés

Fuentes de financiamiento:

Autofinanciado

Citar como: Saldaña Orejón IM, Benites Ricra MA, Ortiz Canasa FJ. Estabilidad de constituyentes bioquímicos conservados en dos tipos de tubos primarios: estudio mediante el criterio combinado de variabilidad analítica y biológica. An Fac med. 2018;79(2):181-83

DOI: http://dx.doi.org/10.15381/anales. v79i2.14947

\section{An Fac med. 2018;79(2):181-83 / http://dx.doi.org/10.15381/anales.v79i2.14947}

\section{Sr. Editor}

La demora en la medición de una magnitud bioquímica puede originar errores en la interpretación de los resultados debido a la variación de los componentes de la muestra, por tal razón queremos compartir un estudio cuyo objetivo fue determinar la estabilidad de 27 constituyentes bioquímicos conservados a temperatura de refrigeración en dos tipos de tubos primarios, valorados mediante el criterio combinado de variabilidad analítica y biológica ${ }^{1}$.

Se recolectaron 22 muestras de sangre en dos tipos de tubos: 11 muestras en tubo sin gel separador y 11 muestras en tubos con gel separador, ambos tubos de la marca BD Vacutainer ${ }^{\circledR}$ con sistema al vacío, de material plástico (polietilen teraftalato) y revestidos con micro partículas de sílice para acelerar el proceso de coagulación. Posterior a la centrifugación de las muestras, los constituyentes fueron determinados por duplicado en el analizador ADVIA 1800 (Siemens Diagnostics ${ }^{\circledR}$ ), considerando a la primera determinación como el tiempo de 0 horas, posteriormente también fueron procesadas a las 6 horas y durante 7 días consecutivos con un intervalo de 24 horas. Inmediatamente después de cada una de las series analíticas, las muestras se conservaron en refrigeración a $4 \pm 2{ }^{\circ} \mathrm{C}$, sin ventilación, tapados y en condiciones de oscuridad. La estabilidad de los constituyentes se determinó calculando el promedio de los datos obtenidos por duplicado y transformándolos en sus correspondientes porcentajes, considerándose la concentración obtenida a tiempo 0 horas como el 100\%.

Para la evaluación de la estabilidad fijamos los límites de estabilidad mediante la siguiente ecuación².

$$
L E= \pm \sqrt{(1,65 * \mathrm{CVa})^{2}+(0,5 * \mathrm{CVb})^{2}}
$$

Donde el CVa representa el coeficiente de variación analítica interdía correspondiente a los resultados del control de calidad interno obtenidos durante los siete meses anteriores a la realización del estudio y el CVb representa la variación biológica intraindividual de cada constituyente ${ }^{3}$.

Al concluir el estudio, 17 constituyentes no superaron los límites de estabilidad para ambos tipos de tubos: urea, ácido úrico, colesterol total, aspartato aminotransferasa, alanina aminotrans- 


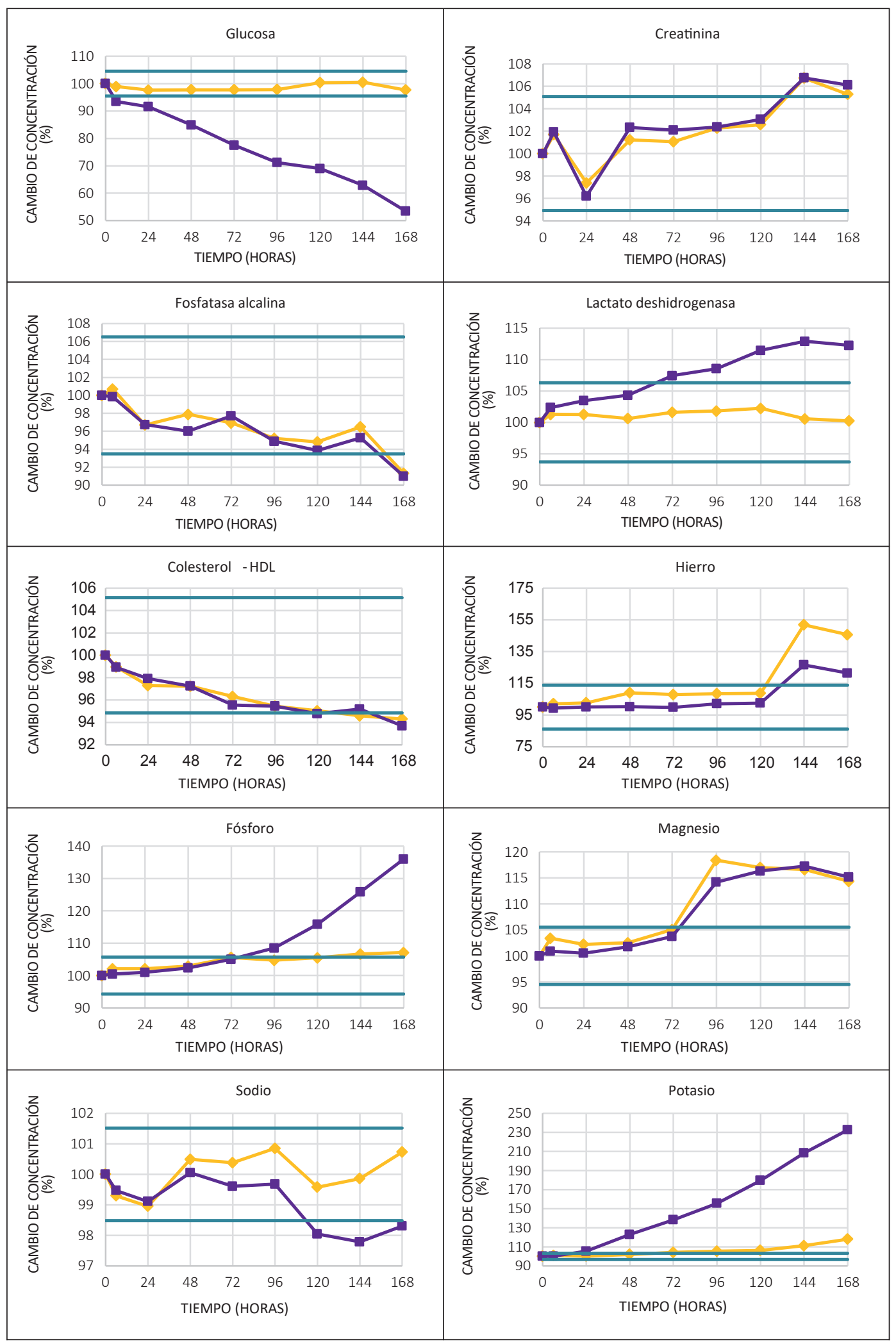

$(\neg)$ Tubo con gel separador, (- $)$ Tubo sin gel separador, $(\boldsymbol{C})$ Límites de estabilidad

Figura 1. Curva de variación de la concentración porcentual de los 10 constituyentes que superaron los intervalos de estabilidad. 
ferasa, LDL colesterol, triglicéridos, gamma glutamiltransferasa, bilirrubina total, creatina cinasa, proteínas totales, albúmina, amilasa, lipasa, cloro, calcio y transferrina. Mientras que los constituyentes creatinina, fosfatasa alcalina, HDL colesterol, hierro, fósforo, magnesio y potasio, excedieron los intervalos de estabilidad para los dos tipos de tubos. Adicionalmente, los constituyentes glucosa, láctico deshidrogenasa y sodio resultaron inestables para los tubos sin gel a partir de las 6, 72 y 120 horas respectivamente. En la figura 1 se representa la curva de variación de la concentración porcen- tual de los 10 constituyentes que superaron los intervalos de estabilidad.

El empleo de pautas para establecer los límites de estabilidad derivado únicamente del criterio de imprecisión analítica o variabilidad biológica generan límites restrictivos para métodos muy precisos o con escasa variabilidad biológica, lo que ocasiona un rechazo innecesario de solicitudes cuando se requiera realizar repeticiones o se adicionen más pruebas al petitorio original ${ }^{4,5}$. Recomendamos que cada laboratorio evalúe la estabilidad de los constituyentes bioquímicos utilizando sus propias metodologías y desempeño analítico.

\section{REFERENCIAS BIBLIOGRÁFICAS}

1. Cruz LM, Monge N, Valero J, Fuentes X. Estabilidad de las magnitudes bioquímicas. Química Clínica. 2002;21(2):52-61.

2. Zhang DJ, Elswick RK, Miller WG, Bailey JL. Effect of serum-clot contact time on clinical chemistry laboratory results. Clin Chem. 1998; 44(6 Pt1):1325-1333.

3. Westgard QC. [homepage on the Internet]. Desirable Biological Variation Database specifications. Madison: Westgard QC; c2009 [actualizado 2014; citado 15 Set 2017]. Disponible en: https://www.westgard.com/ biodatabase1.htm

4. Alcaraz Quiles J, Rico Santana N, Bedini Chesa JL. Estabilidad de 27 magnitudes bioquímicas en muestras de suero conservadas en refrigeración. Rev Lab Clínico. 2014;7(1):9-16.

5. Caracciolo MB, Muzietti SD, Pandolfo MS, Negri GA, Bustos DN. Estabilidad de muestras conservadas en tubo primario: un estudio de 25 analitos de química clínica. Acta bioquím. clín. latinoam. 2007;41(3):353-358. 